Lecture Notes in Electrical Engineering 365

Felix Pasila

Yusak Tanoto

Resmana Lim

Murtiyanto Santoso

Nemuel Daniel Pah

Editors

Proceedings of Second International Conference on Electrical Systems, Technology and Information 2015 (ICESTI 2015) 


\section{Lecture Notes in Electrical Engineering}

\section{Volume 365}

\section{Board of Series editors}

Leopoldo Angrisani, Napoli, Italy

Marco Arteaga, Coyoacán, México

Samarjit Chakraborty, München, Germany

Jiming Chen, Hangzhou, P.R. China

Tan Kay Chen, Singapore, Singapore

Rüdiger Dillmann, Karlsruhe, Germany

Haibin Duan, Beijing, China

Gianluigi Ferrari, Parma, Italy

Manuel Ferre, Madrid, Spain

Sandra Hirche, München, Germany

Faryar Jabbari, Irvine, USA

Janusz Kacprzyk, Warsaw, Poland

Alaa Khamis, New Cairo City, Egypt

Torsten Kroeger, Stanford, USA

Tan Cher Ming, Singapore, Singapore

Wolfgang Minker, Ulm, Germany

Pradeep Misra, Dayton, USA

Sebastian Möller, Berlin, Germany

Subhas Mukhopadyay, Palmerston, New Zealand

Cun-Zheng Ning, Tempe, USA

Toyoaki Nishida, Sakyo-ku, Japan

Bijaya Ketan Panigrahi, New Delhi, India

Federica Pascucci, Roma, Italy

Tariq Samad, Minneapolis, USA

Gan Woon Seng, Nanyang Avenue, Singapore

Germano Veiga, Porto, Portugal

Haitao Wu, Beijing, China

Junjie James Zhang, Charlotte, USA 
"Lecture Notes in Electrical Engineering (LNEE)" is a book series which reports the latest research and developments in Electrical Engineering, namely:

- Communication, Networks, and Information Theory

- Computer Engineering

- Signal, Image, Speech and Information Processing

- Circuits and Systems

- Bioengineering

LNEE publishes authored monographs and contributed volumes which present cutting edge research information as well as new perspectives on classical fields, while maintaining Springer's high standards of academic excellence. Also considered for publication are lecture materials, proceedings, and other related materials of exceptionally high quality and interest. The subject matter should be original and timely, reporting the latest research and developments in all areas of electrical engineering.

The audience for the books in LNEE consists of advanced level students, researchers, and industry professionals working at the forefront of their fields. Much like Springer's other Lecture Notes series, LNEE will be distributed through Springer's print and electronic publishing channels.

More information about this series at http://www.springer.com/series/7818 
Felix Pasila $\cdot$ Yusak Tanoto

Resmana Lim - Murtiyanto Santoso

Nemuel Daniel Pah

Editors

Proceedings of Second

International Conference

on Electrical Systems,

Technology and Information

2015 (ICESTI 2015)

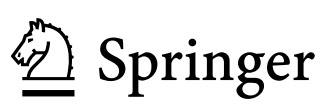




\section{Editors}

Felix Pasila

Department of Electrical Engineering

Petra Christian University

Surabaya

Indonesia

Yusak Tanoto

Department of Electrical Engineering

Petra Christian University

Surabaya

Indonesia

Resmana Lim

Department of Electrical Engineering

Petra Christian University

Surabaya

Indonesia

\author{
Murtiyanto Santoso \\ Department of Electrical Engineering \\ Petra Christian University \\ Surabaya \\ Indonesia
}

Nemuel Daniel Pah

University of Surabaya

Surabaya

Indonesia

ISSN 1876-1100

ISSN 1876-1119 (electronic)

Lecture Notes in Electrical Engineering

ISBN 978-981-287-986-8

ISBN 978-981-287-988-2 (eBook)

DOI 10.1007/978-981-287-988-2

\section{Library of Congress Control Number: 2015960766}

(C) Springer Science+Business Media Singapore 2016

This work is subject to copyright. All rights are reserved by the Publisher, whether the whole or part of the material is concerned, specifically the rights of translation, reprinting, reuse of illustrations, recitation, broadcasting, reproduction on microfilms or in any other physical way, and transmission or information storage and retrieval, electronic adaptation, computer software, or by similar or dissimilar methodology now known or hereafter developed.

The use of general descriptive names, registered names, trademarks, service marks, etc. in this publication does not imply, even in the absence of a specific statement, that such names are exempt from the relevant protective laws and regulations and therefore free for general use.

The publisher, the authors and the editors are safe to assume that the advice and information in this book are believed to be true and accurate at the date of publication. Neither the publisher nor the authors or the editors give a warranty, express or implied, with respect to the material contained herein or for any errors or omissions that may have been made.

Printed on acid-free paper

This Springer imprint is published by SpringerNature

The registered company is Springer Science+Business Media Singapore Pte Ltd. 


\section{Contents}

\section{Part I Invited Speaker}

1 Computational Intelligence Based Regulation of the DC Bus in the On-grid Photovoltaic System . . . . . . . . . . . . 3

Mauridhi Hery Purnomo, Iwan Setiawan and Ardyono Priyadi

2 Virtual Prototyping of a Compliant Spindle for Robotic Deburring . . . . . . . . . . . . . . . . . . . . . . . . . . . . 17

Giovanni Berselli, Marcello Pellicciari, Gabriele Bigi and Angelo O. Andrisano

3 A Concept of Multi Rough Sets Defined on Multi-contextual Information Systems. Rolly Intan

Part II Technology Innovation in Robotics Image Recognition and Computational Intelligence Applications

4 Coordinates Modelling of the Discrete Hexapod Manipulator via Artificial Intelligence.

Felix Pasila and Roche Alimin

5 An Object Recognition in Video Image Using Computer

Vision

Sang-gu Kim, Seung-hoon Kang, Joung Gyu Lee and Hoon Jae Lee

6 Comparative Study on Mammogram Image Enhancement Methods According to the Determinant of Radiography Image Quality .

Erna Alimudin, Hanung Adi Nugroho and Teguh Bharata Adji 
7 Clustering and Principal Feature Selection Impact

for Internet Traffic Classification Using K-NN . . . . . . . . . . . . 75

Trianggoro Wiradinata and P. Adi Suryaputra

8 Altitude Lock Capability Benchmarking: Type 2 Fuzzy, Type 1 Fuzzy, and Fuzzy-PID with Extreme Altitude

Change as a Disturbance . . . . . . . . . . . . . . . . 83

Hendi Wicaksono, Yohanes Gunawan, Cornelius Kristanto

and Leonardie Haryanto

9 Indonesian Dynamic Sign Language Recognition at Complex

Background with 2D Convolutional Neural Networks . . . . . . . . . 91

Nehemia Sugianto and Elizabeth Irenne Yuwono

10 Image-Based Distance Change Identification by Segment

Correlation . . . . . . . . . . . . . . . . . . . . . 99

Nemuel Daniel Pah

11 Situation Awareness Assessment Mechanism

for a Telepresence Robot . . . . . . . . . . . . . . . . . . . . . . . 107

Petrus Santoso and Handry Khoswanto

12 Relevant Features for Classification of Digital Mammogram

Images. . . . . . . . . . . . . . . . . . . . . . . . 115

Erna Alimudin, Hanung Adi Nugroho and Teguh Bharata Adji

13 Multi-objective Using NSGA-2 for Enhancing

the Consistency-Matrix.

Abba Suganda Girsang, Sfenrianto and Jarot S. Suroso

14 Optimization of AI Tactic in Action-RPG Game . . . . . . . . . . . . 131

Kristo Radion Purba

15 Direction and Semantic Features for Handwritten Balinese

Character Recognition System

Luh Putu Ayu Prapitasari and Komang Budiarta

16 Energy Decomposition Model Using Takagi-Sugeno

Neuro Fuzzy

Yusak Tanoto and Felix Pasila

17 Odometry Algorithm with Obstacle Avoidance

on Mobile Robot Navigation.

Handry Khoswanto, Petrus Santoso and Resmana Lim 
Part III Technology Innovation in Electrical Engineering, Electric Vehicle and Energy Management

18 Vision-Based Human Position Estimation and Following Using an Unmanned Hexarotor Helicopter . . . . . . . . . . . . . 165 Jung Hyun Lee and Taeseok Jin

19 The Role of Renewable Energy: Sumba Iconic Island, an Implementation of 100 Percent Renewable Energy by 2020 . . . . . 173 Abraham Lomi

20 Electromechanical Characterization of Bucky Gel Actuator Based on Polymer Composite PCL-PU-CNT for Artificial Muscle . . . . . . . . . . . . . . . . . . . . . . 185 Yudan Whulanza, Andika Praditya Hadiputra, Felix Pasila and Sugeng Supriadi

21 A Single-Phase Twin-Buck Inverter . . . . . . . . . . . . . . . . . 193 Hanny H. Tumbelaka

22 Performance Comparison of Intelligent Control of Maximum Power Point Tracking in Photovoltaic System. . . . . . . . . . . . . . . . . . . . . . . . . 203 Daniel Martomanggolo Wonohadidjojo

23 Vehicle Security and Management System on GPS Assisted Vehicle Using Geofence and Google Map Lanny Agustine, Egber Pangaliela and Hartono Pranjoto

24 Security and Stability Improvement of Power System Due to Interconnection of DG to the Grid .

Ni Putu Agustini, Lauhil Mahfudz Hayusman, Taufik Hidayat and I. Made Wartana

25 Solar Simulator Using Halogen Lamp for PV Research . . . . . . . . 239 Aryuanto Soetedjo, Yusuf Ismail Nakhoda, Abraham Lomi and Teguh Adi Suryanto

26 Artificial Bee Colony Algorithm for Optimal Power Flow on Transient Stability of Java-Bali $500 \mathrm{KV}$.

Irrine Budi Sulistiawati and M. Ibrahim Ashari

27 Sizing and Costs Implications of Long-Term Electricity Planning: A Case of Kupang City, Indonesia.

Daniel Rohi and Yusak Tanoto

28 Dynamic Simulation of Wheel Drive and Suspension System in a Through-the-Road Parallel Hybrid Electric Vehicle . . . . . . . 263 Mohamad Yamin, Cokorda P. Mahandari and Rasyid H. Sudono 
29 A Reliable, Low-Cost, and Low-Power Base Platform for Energy Management System . . . . . . . . . . . . . . . . . 271

Henry Hermawan, Edward Oesnawi and Albert Darmaliputra

30 Android Application for Distribution Switchboard Design . . . . . . 279 Julius Sentosa Setiadji, Kevin Budihargono and Petrus Santoso

Part IV Technology Innovation in Electronic, Manufacturing, Instrumentation and Material Engineering

31 Adaptive Bilateral Filter for Infrared Small Target Enhancement .

Tae Wuk Bae and Hwi Gang Kim

32 Innovative Tester for Underwater Locator Beacon Used in Flight/Voyage Recorder (Black Box) . . . . . . . . . . . . . . . . 299 Hartono Pranjoto and Sutoyo

33 2D CFD Model of Blunt NACA 0018 at High Reynolds Number for Improving Vertical Axis Turbine Performance . . . . . . 309 $\mathrm{Nu}$ Rhahida Arini, Stephen R. Turnock and Mingyi Tan

34 Recycling of the Ash Waste by Electric Plasma Treatment to Produce Fibrous Materials

S.L. Buyantuev, A.S. Kondratenko, E.T. Bazarsadaev and A.B. Khmelev

35 Performance Evaluation of Welded Knitted E-Fabrics for Electrical Resistance Heating.

Senem Kursun Bahadir, Ozgur Atalay, Fatma Kalaoglu, Savvas Vassiliadis and Stelios Potirakis

36 IP Based Module for Building Automation System

J.D. Irawan, S. Prasetio and S.A. Wibowo

37 Influence of CTAB and Sonication on Nickel Hydroxide Nanoparticles Synthesis by Electrolysis at High Voltage. . . . . . . . 345 Yanatra Budipramana, Suprapto, Taslim Ersam and Fredy Kurniawan

38 Waste Industrial Processing of Boron-Treated by Plasma Arc to Produce the Melt and Fiber Materials

S.L. Buyantuev, Ning Guiling, A.S. Kondratenko, Junwei Ye,

E.T. Bazarsadaev, A.B. Khmelev and Shuhong Guo

39 Design of Arrhythmia Detection Device Based on Fingertip

Pulse Sensor

R. Wahyu Kusuma, R. Al Aziz Abbie and Purnawarman Musa 
40 Analysis of Fundamental Frequency and Formant Frequency for Speaker 'Makhraj' Pronunciation with DTW Method . . . . . . . 373 Muhammad Subali, Miftah Andriansyah and Christanto Sinambela

41 Design and Fabrication of "Ha (Un)" Shape-Slot Microstrip Antenna for WLAN $2.4 \mathbf{G H z} \ldots \ldots \ldots \ldots 383$ Srisanto Sotyohadi, Sholeh Hadi Pramono and Moechammad Sarosa

42 Investigation of the Electric Discharge Machining on the Stability of Coal-Water Slurries . . . . . . . . . . . . . . . . 393 S.L. Buyantuev, A.B. Khmelev, A.S. Kondratenko and F.P. Baldynova

43 A River Water Level Monitoring System Using Android-Based Wireless Sensor Networks for a Flood Early Warning System . . . . 401 Riny Sulistyowati, Hari Agus Sujono and Ahmad Khamdi Musthofa

44 The Influence of Depth of Cut, Feed Rate and Step-Over on Surface Roughness of Polycarbonate Material in Subtractive Rapid Prototyping

The Jaya Suteja

45 Adaptive Cars Headlamps System with Image Processing and Lighting Angle Control .

William Tandy Prasetyo, Petrus Santoso and Resmana Lim

46 Changes in the Rheological Properties and the Selection of a Mathematical Model of the Behavior of Coal-Water Slurry During Transport and Storage. . . . . . . . . . . . . . . . 423 S.L. Buyantuev, A.B. Khmelev and A.S. Kondratenko

47 Design of a Fetal Heartbeat Detector.

Nur Sultan Salahuddin, Sri Poernomo Sari, Paulus A. Jambormias and Johan Harlan

Part V Technology Innovation in Internet of Things and Its Applications

48 Network Traffic and Security Event Collecting System Hee-Seung Son, Jin-Heung Lee, Tae-Yong Kim and Sang-Gon Lee

49 Paper Prototyping for BatiKids: A Technique to Examine Children's Interaction and Feedback in Designing a Game-Based Learning . 
50 Tracing Related Scientific Papers by a Given Seed

Paper Using Parscit . . . . . . . . . . . . . . . . . . . . . . . . . 457

Resmana Lim, Indra Ruslan, Hansin Susatya, Adi Wibowo,

Andreas Handojo and Raymond Sutjiadi

51 Factors Affecting Edmodo Adoption as Online Learning

Medium . . . . . . . . . . . . . . . . . . . . . . . . . . . 465

Iwa Sungkono Herlambangkoro and Trianggoro Wiradinata

52 Principal Feature Selection Impact for Internet Traffic

Classification Using Naïve Bayes . . . . . . . . . . . . . . . . . . . . . . 475

Adi Suryaputra Paramita

53 Study on the Public Sector Information (PSI) Service Model

for Science and Technology Domain in South Korea . . . . . . . . . . . 481

Yong Ho Lee

54 Digital Natives: Its Characteristics and Challenge

to the Library Service Quality . . . . . . . . . . . . . . . . . . . . . . . . 487

Siana Halim, Felecia, Inggrid, Dian Wulandari

and Demmy Kasih

55 Web-Based Design of the Regional Health Service System

in Bogor Regency.

B. Sundari, Revida Iriana and Bertilia Lina Kusrina

56 Security Handwritten Documents Using Inner Product . . . . . . . . 501 Syaifudin and Dian Pratiwi

57 Augmented Reality Technique for Climate Change Mitigation . . . . 511 Ruswandi Tahrir

58 Cyber Security for Website of Technology Policy Laboratory . . . . 521 Jarot S. Suroso

59 TAM-MOA Hybrid Model to Analyze the Acceptance of Smartphone for Pediatricians in Teaching Hospital in Indonesia.

Oktri Mohammad Firdaus, Nanan Sekarwana,

T.M.A. Ari Samadhi and Kah Hin Chai

60 Development of the Remote Instrumentation Systems

Based on Embedded Web to Support Remote Laboratory . . . . . . 537

F. Yudi Limpraptono and Irmalia Suryani Faradisa

61 Enhancing University Library Services with Mobile Library Information System . . . . . . . . . . . . . . . . . . . . . . . . . . . 545

Singgih Lukman Anggana and Stephanus Eko Wahyudi 
62 Multi Level Filtering to Classify and Block Undesirable Explicit Material in Website .

Mohammad Iqbal, Hifshan Riesvicky, Hasma Rasjid and Yulia Charli

63 Query Rewriting and Corpus of Semantic Similarity as Encryption Method for Documents in Indonesian Language. . 565

Detty Purnamasari, Rini Arianty, Diana Tri Susetianingtias and Reni Diah Kusumawati

64 Securing Client-Server Application Design for Information System Inventory . . . . . . . . . . . . . . . . . . . . . . . . 573 Ibnu Gunawan, Djoni Haryadi Setiabudi, Agustinus Noertjahyana and Yongky Hermawan

Part VI Technology Innovation in Information, Modelling and Mobile Applications

65 Analyzing Humanitarian Logistic Coordination

for Disaster Relief in Indonesia.

Tanti Octavia, I. Gede Agus Widyadana and Herry Christian Palit

66 Surakarta Cultural Heritage Management Based on Geographic Information Systems

Ery Dewayani and M. Viny Christanti

67 Gray Code of Generating Tree of $\boldsymbol{n}$ Permutation with $\boldsymbol{m}$ Cycles

Sulistyo Puspitodjati, Henny Widowati and Crispina Pardede

68 Android and iOS Hybrid Applications for Surabaya Public Transport Information

Djoni Haryadi Setiabudi and Lady Joanne Tjahyana

69 Games and Multimedia Implementation on Heroic Battle of Surabaya: An Android Based Mobile Device Application.

Andreas Handojo, Resmana Lim, Justinus Andjarwirawan and Sandy Sunaryo

70 Streamlining Business Process: A Case Study of Optimizing a Business Process to Issue a Letter of Assignment for a Lecturer in the University of Surabaya . . . . . . . . . . . . . 631 S.T. Jimmy

71 Design of Adventure Indonesian Folklore Game

Kartika Gunadi, Liliana and Harvey Tjahjono 
72 Measuring the Usage Level of the IE Tools in SMEs

Using Malcolm Baldrige Scoring System . . . . . . . . . . . . . . . . . . 649

I. Nyoman Sutapa, Togas W.S. Panjaitan and Jani Rahardjo

73 Enumeration and Generation Aspects of Tribonacci Strings. . . . . 659 Maukar, Asep Juarna and Djati Kerami

74 A Leukocyte Detection System Using Scale Invariant Feature Transform Method . . . . . . . . . . . . . . . . . . . . . . . 669 Lina and Budi Dharmawan

75 The Diameter of Enhanced Extended Fibonacci Cube Interconnection Networks.

Ernastuti, Mufid Nilmada and Ravi Salim

76 Prototype Design of a Realtime Monitoring System of a Fuel Tank at a Gas Station Using an Android-Based Mobile Application . . . . . . . . . . . . . . . . . . . 685 Riny Sulityowati and Bayu Bhahtra Kurnia Rafik 


\section{Introduction}

This book includes the original, peer-reviewed research papers from the 2nd International Conference on Electrical Systems, Technology and Information (ICESTI 2015), held during 9-12 September 2015, at Patra Jasa Resort \& Villas Bali, Indonesia.

The primary objective of this book is to provide references for dissemination and discussion of the topics that have been presented in the conference. This volume is unique in that it includes work related to Electrical Engineering, Technology and Information towards their sustainable development. Engineers, researchers as well as lecturers from universities and professionals in industry and government will gain valuable insights into interdisciplinary solutions in the field of Electrical Systems, Technology and Information, and its applications.

The topics of ICESTI 2015 provide a forum for accessing the most up-to-date and authoritative knowledge and the best practices in the field of Electrical Engineering, Technology and Information towards their sustainable development. The editors selected high quality papers from the conference that passed through a minimum of three reviewers, with an acceptance rate of $50.6 \%$.

In the conference there were three invited papers from keynote speakers, whose papers are also included in this book, entitled: "Computational Intelligence based Regulation of the DC bus in the On-Grid Photovoltaic System", "Virtual Prototyping of a Compliant Spindle for Robotic Deburring" and "A Concept of Multi Rough Sets Defined on Multi-Contextual Information Systems".

The conference also classified the technology innovation topics into five parts: "Technology Innovation in Robotics, Image Recognition and Computational Intelligence Applications", "Technology Innovation in Electrical Engineering, Electric Vehicle and Energy Management", "Technology Innovation in Electronic, Manufacturing, Instrumentation and Material Engineering", "Technology Innovation in Internet of Things and Its Applications" and "Technology Innovation in Information, Modeling and Mobile Applications".

In addition, we are really thankful for the contributions and for the valuable time spent in the review process by our Advisory Boards, Committee Members and Reviewers. Also, we appreciate our collaboration partners (Petra Christian 
University, Surabaya; Gunadarma University, Jakarta; UBAYA, Surabaya, University of Ciputra, Surabaya, Institute of National Technology, Malang and LNEE Springer, Germany), our supporting institution (Oulu University, Finland, Widya Mandala Catholic University, Surabaya and Dongseo University, Korea) and our sponsors (Continuing Education Centre, Petra Christian University, Surabaya and Patrajasa Resort Hotel, Bali).

On behalf of the editors

Felix Pasila 


\title{
Chapter 11 \\ Situation Awareness Assessment \\ Mechanism for a Telepresence Robot
}

\author{
Petrus Santoso and Handry Khoswanto
}

\begin{abstract}
There are several metrics to evaluate about the sophistication of a telepresence robot. One of them is concerning operator performance especially about Situation Awareness (SA). There are many ways to enhance their awareness about situation and environment in the remote side. To do an evaluation, this paper want to propose a mechanism to do an SA assessment on a telepresence robot. The proposed mechanism is basically based on a query that randomly displayed to the operator. The operator will quickly respond to the query on the telepresence robot user interface. The query is used to assess SA, therefore all SA requirements from perception to prediction will be accommodated. The mechanism is developed and implemented on the telepresence robot prototype. Some users tried to operate and respond to the assessment queries. The user response can be stored and retrieved to be processed further to do an SA assessment. The mechanism seems to be working and can be easily deployed to another telepresence robot as long as the protocol is compatible.
\end{abstract}

Keywords Telepresence $\cdot$ Robotic $\cdot$ Situation awareness

\subsection{Introduction}

To implement a functionally working telepresence robot, there are several metrics that need to be taken care of. Three groups of common metrics have been elaborated by Steinfeld et al. [1] namely: System Performance, Operator Performance and Robot Performance. System performance assessment concern with how well the human(s) and the robot(s) perform as a team. Operator Performance concern with situation awareness, workload and accuracy of mental models of device operation. Robot performance deal with robot self-awareness, human awareness and autonomy.

P. Santoso $(\bowtie) \cdot H$. Khoswanto

Department of Electrical Engineering, Petra Christian University,

JL. Siwalankerto 121-131, Surabaya 60236, Indonesia

e-mail: petrus@petra.ac.id

(C) Springer Science+Business Media Singapore 2016

F. Pasila et al. (eds.), Proceedings of Second International Conference

on Electrical Systems, Technology and Information 2015 (ICESTI 2015),

Lecture Notes in Electrical Engineering 365, DOI 10.1007/978-981-287-988-2_11 
This paper wants to focus on the situation awareness (SA) aspect of operator performance. By definition, SA is an understanding of the environment state (not ignoring the relevant system parameters) [2]. It is critical to subsequent decision making, operator performance and workload in many dynamic control tasks [3, 4]. Basically SA is a very important metric for controlling dynamic system. In this case, it is very important for a telepresence robot.

There are three defined levels of SA, namely perception, comprehension and projection [2]. Perception also called SA level 1. This level is achieved if the human operator is able to perceive the information needed to do the task via the interface. This is the basic level of SA. Comprehension is the next level, it is also called SA level 2. The human operator can interpret the perceived information correctly, alone or combined with other information at hand. Projection is the highest level, it is also called SA level 3. It is the ability to predict future event based on the current situation. To achieve the highest level of SA, the user interface must be designed to facilitate the acquisition of all the needed information.

To evaluate SA, there is a common query-based tool known as "Situation Awareness Global Assessment Technique" (SAGAT) [2]. The important aspect of using SAGAT is to do a detailed task analysis. The result of task analysis is used to formulate appropriate operator queries. These queries are used to measure SA [1]. The usual scenario using SAGAT is performed using a simulator. At a certain point of interest, the simulator is frozen randomly then the operator is directed to quickly answer queries about their current perception of the situation. All the queries should contain all SA requirements from level 1 (perception), level 2 (comprehension) and level 3 (projection).

In the case of telepresence robot, it is possible to use simulator to assess SA. In the other hand, the idea of this paper is to assess SA in real world scenario. Therefore there is a need to develop a mechanism to assess SA that enable the user to respond as fast as possible and not quite intrusive. The work presented in this paper focuses on the development of mechanism to assess SA, specifically for a telepresence robot.

\subsection{System Design}

The prototype of telepresence robot used in the development of SA assessment mechanism is implemented based on the ASP framework as depicted on Fig. 11.1.

The first step of the framework is defining an architecture based on a requirement analysis. Architecture design will be followed by the service design. Service design presents all of the Service Elements needed by the system. The last step is outlined the whole system protocol. The protocol will implement all of the Service Primitives on each Service Elements [5]. 


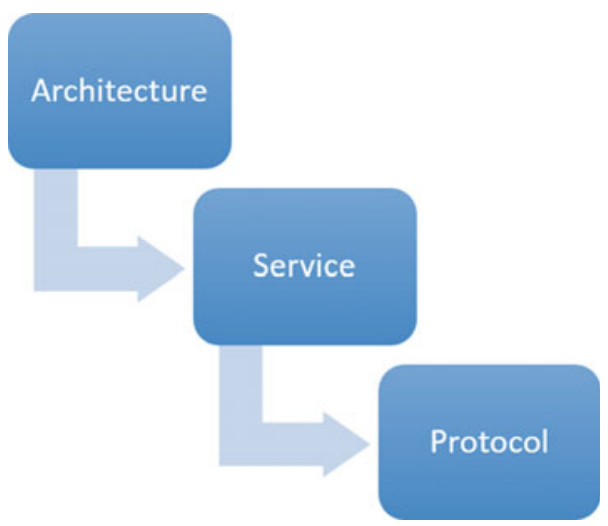

Fig. 11.1 ASP framework

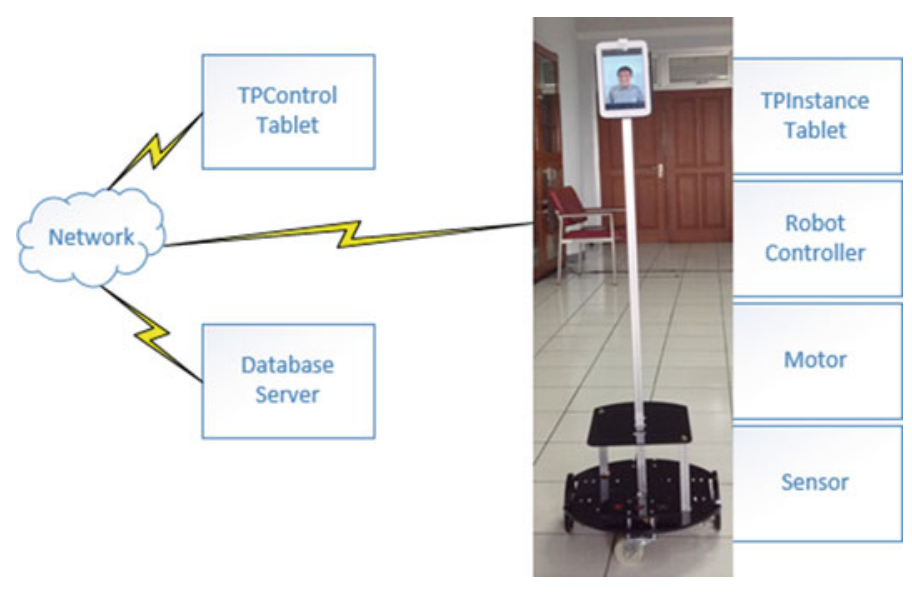

Fig. 11.2 Architecture of telepresence robot

The architecture of the telepresence robot are shown on Fig. 11.2. The system mainly consist of three entities, namely: TPControl Tablet, Telepresence Robot controlled by TPInstance Tablet and a database server. All three are connected through a computer network, whether it is local or global.

TPControl Tablet is the main control unit held by telepresence operator. This tablet is used to give command to telepresence robot and receive information given by telepresence robot. TPInstance Tablet is used as the receiving unit. It receives command from TPControl Tablet, interprets the received command and drives the robot accordingly. It also collects information from the available sensors and sends 
Table 11.1 Service primitive

\begin{tabular}{|c|c|}
\hline Service element & Service primitive (SP) \\
\hline \multirow[t]{6}{*}{ Movement } & Forward_Req \\
\hline & Backward_Req \\
\hline & Left_Req \\
\hline & Right_Req \\
\hline & Stop_Req \\
\hline & Move_Ack \\
\hline \multirow[t]{2}{*}{ Monitoring } & Video_Req \\
\hline & Video_Ack \\
\hline \multirow[t]{4}{*}{ Video Call } & Call_Req \\
\hline & Disc_Req \\
\hline & Add_Recipient_Req \\
\hline & Remove_Recipient_Req \\
\hline \multirow[t]{4}{*}{ Auxiliary } & Send_Robot_Status \\
\hline & Send_Aux_Req \\
\hline & Get_Aux_Req \\
\hline & Aux_Ack \\
\hline \multirow[t]{4}{*}{ SA Assessment } & $\begin{array}{l}\text { SAQuery_Begin } \\
\text { SAQuery_Req }\end{array}$ \\
\hline & SAQuery_Respond \\
\hline & SAQuery_Store \\
\hline & $\begin{array}{l}\text { SAQuery_Ack } \\
\text { SAQuery_End }\end{array}$ \\
\hline
\end{tabular}

the information to the TPControl Tablet. The Database server is added to the system to collect user's responds concerning SA Query.

Focusing on the additional service for SA assessment, the revised service design from [5] is shown in the service primitives list on Table 11.1. The additional service element is printed in bold.

The SA Assessment service element deals with SA assessment mechanism. It is a sequence of SPs represent notification to the TPInstance Tablet and information exchange between TPControl Tablet and database server.

As for the protocol, a time sequence diagram for SA Assessment service is outlined at Fig. 11.3. The involved entities are TPControl Tablet, TPInstance Tablet and the database server.

The depicted time sequence diagram depicted the flow of SPs throughout SA Query process. 
Fig. 11.3 SAQuery time

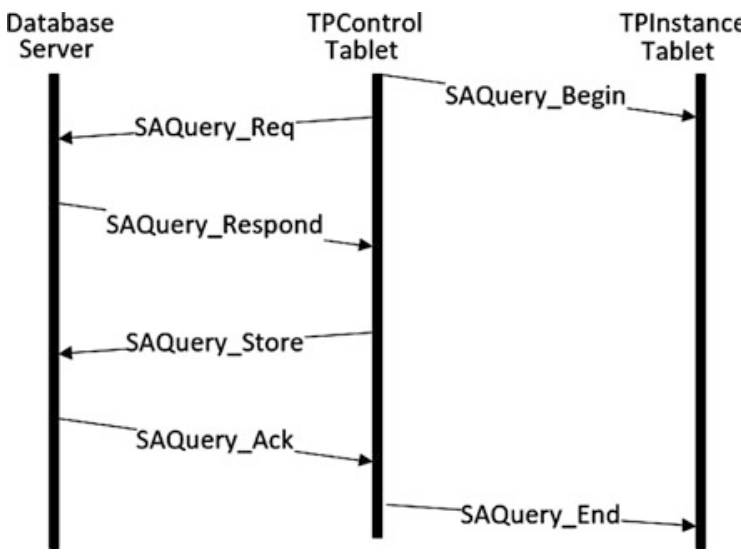

\subsection{SA Assessment Mechanism}

The proposed SA Assessment tool is the SAGAT query tool. Some discussions have been done to do a detailed task analysis of telepresence robot. A database of SA Query has been developed. Some sample questions can be seen on Fig. 11.4.

The detailed SA Assessment mechanism can be seen also on Fig. 11.3. SAQuery_Begin tells the TPInstance Tablet to pause all operations during SA Assessment. TPControl then retrieves SA questions from database server with

\section{(a)}

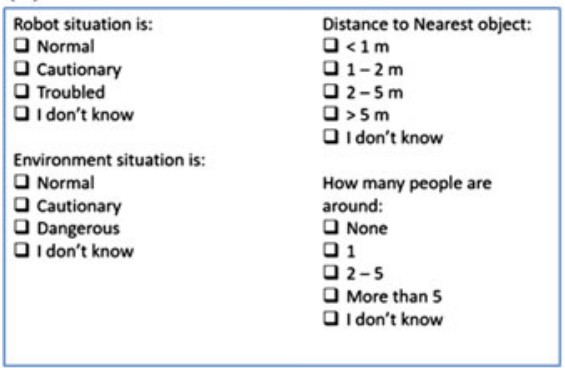

\section{(b)}

\begin{tabular}{|l|}
\hline Check all that apply: \\
Crowded situation \\
At the intersection \\
Exit from the room \\
Entering a room \\
$\square$ Nearby obstacles: \\
$\square$ Ahead \\
Behind \\
Beside \\
Nearest People \\
$\square$ In the left side \\
In the right side \\
Facing the robot \\
In the same direction \\
\end{tabular}

(c)
Is it safe
$\square$ Yes
$\square$ No
I don't know
Write a short observation about robot situation:

Fig. 11.4 SA Query examples a SA Level 1. b SA Level 2. c SA Level 3 


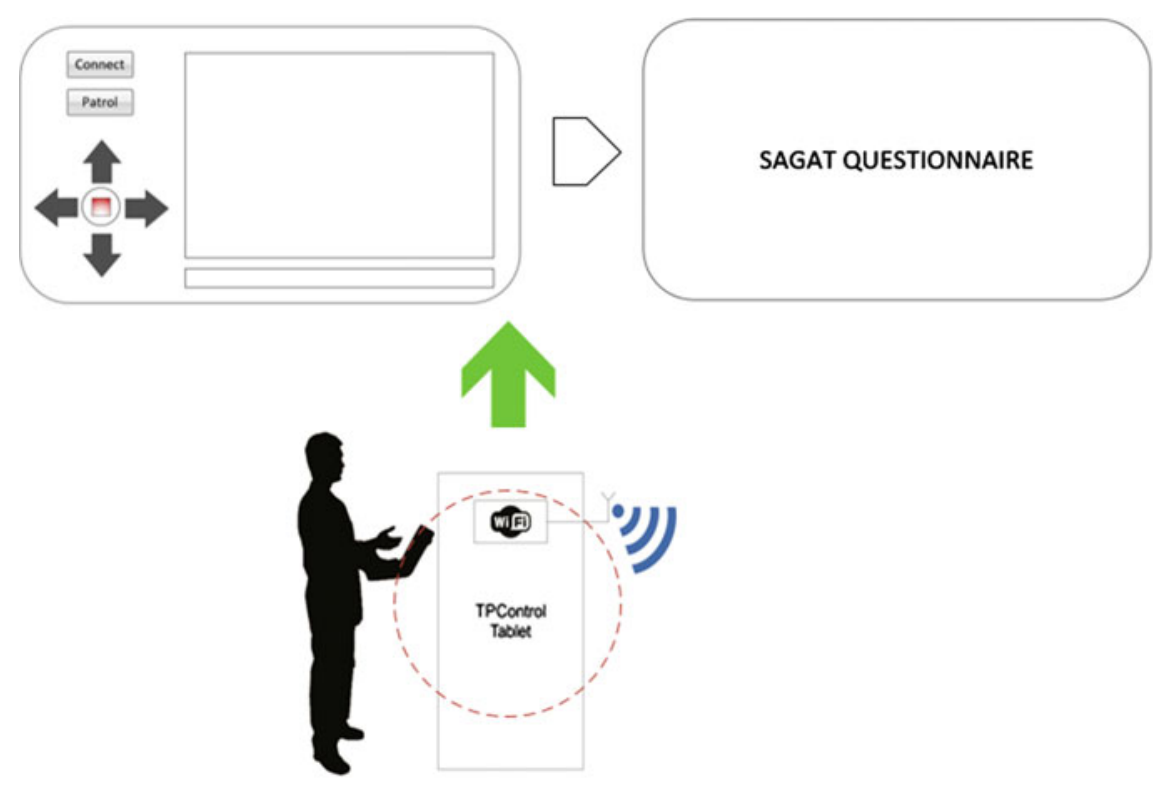

Fig. 11.5 Interface of the SAGAT query

SAQuery_Req. It is responded by SAQuery_Respond. SA questions then displayed on TPControl Tablet. The operator responds, the result is sent to the database server by SAQuery_Store. Acknowledge given by database server and TPControl Tablet tells TPInstance Tablet to resume all operations.

All the depicted mechanisms are mainly happened on the TPControl Tablet. An illustration of the interface as seen by telepresence operator is shown on Fig. 11.5.

\subsection{Result and Discussion}

The SA assessment mechanism has been implemented and deployed to a working telepresence robot. Several operators have been doing beta testing toward the SA assessment mechanism. After several beta testing, the implemented mechanism is considered suitable for real SA assessment process.

The result of beta testing can be summarized as follows. The designed mechanism is work as expected, TPInstance can be paused during SA assessment, SA query and response works, normal operation can be resumed after SA assessment. The time taken for a single SA assessment can be done below $5 \mathrm{~s}$ for each displayed query. Most of the operators considered that the assessment method is still intrusive, but in the other hand can give a good insight on SA performance.

Further improvement can be made to make the mechanism less intrusive. SA query and respond can be stored locally and later synchronized to the database 
server when the situation is possible. This mechanism will reduce the time needed to do an SA query and can be considered less intrusive.

\subsection{Conclusion}

The depicted mechanism in this paper can be considered working without problem. It is easily deployed to all our current prototypes of telepresence robot. It is a useful assessment mechanism to evaluate the performance of telepresence robot, therefore it will be used in all the next iteration of our telepresence robot development.

Acknowledgments This Research is funded by Competitive Research Grants fund of Indonesian Higher Education Directorate under contract No. 30/SP2H/PDSTRL_PEN/LPPM-UKP/IV/2015.

\section{References}

1. Steinfeld, A., Fong, T., Lewis, M., Scholtz, J., Schultz, A., Kaber, D., Goodrich, M.: Common metrics for human-robot interaction (2006)

2. Endsley, M.R.: Measurement of situation awareness in dynamic systems. J. Hum. Factors Ergon. Soc. 37(1), 65-84 (1995)

3. Kaber, D.B., Onal, E., Endsley, M.R.: Design of automation for telerobots and the effect on performance, operator situation awareness, and subjective workload. Hum. Factors Ergon. Manuf. 10(4), 409-430 (2000)

4. Scholtz, J., Antonishek, B., Young, J.: Evaluation of a human-robot interface: development of a situational awareness methodology. In: 37th Annu. Hawaii Int. Conf. Syst. Sci. 2004. Proc. no. C, 1-9 (2004)

5. Santoso, P., Khoswanto, H.: Open protocol framework for telepresence robot. ARPN J. Eng. Appl. Sci. 9(12), 2437-2440 (2014) 